\title{
Study of Greater Sciatic Notch in Sex Determination of Hip Bone by Metric Method
}

\author{
Dr. Suma Dnyanesh ${ }^{1}$, Dr. Dnyanesh $\mathrm{DK}^{2}$, Dr. Phaniraj $\mathrm{S}^{3}$, Dr. Mallikarjun $\mathrm{M}^{3}$, \\ Dr. Vijayashri $\mathrm{BH}^{4}$, Dr. Kapil Amgain ${ }^{1}$ \\ ${ }^{I}$ Department of Anatomy, KLE University's Jawaharlal Nehru Medical College, Belgaum-590010, Karnataka \\ ${ }^{2}$ Department of Paediatrics, KLE University's Jawaharlal Nehru Medical College, Belgaum-590010, Karnataka \\ ${ }^{3}$ Department of Anatomy, VIMS, Bellary-583104, Karnataka, INDIA. \\ ${ }^{4}$ Department of Physiology, KIMS, Hubli, Karnataka, INDIA.
}

\begin{abstract}
Identification of sex of an unknown individual from the skeletal remains is the first and the most important step encountered by the forensic experts and archiologists. The hip bone is considered as an ideal bone for sex determination as it provides the highest accuracy levels. Many workers have studied various metric parameters for sexing of hip bone.

The present study was done with an aim to find out the sex of hip bone using various parameters of greater sciatic notch. For this purpose, 100 dry hip bones were collected from the Department of Anatomy, VIMS, Bellary. Seven different parameters of the greater sciatic notch were used for the study: Maximum width, Maximum depth, Posterior segment, Index I, Index II, Total angle and Posterior angle. All the parameters (especially posterior segment, posterior angle and index II) were found to be highly indicative of sex hip bone by $t$ - test $(p<0.005)$ except the depth.
\end{abstract}

Key Words: Hip bone, Greater sciatic notch, Posterior segment, Posterior angle and Index II.

\section{Introduction}

Determination of sex of an unknown individual is one of the critical questions addressed when human skeletal remains are found both in forensic investigation and studies of past population. Therefore the study of sexual dimorphism of bones in human population is a matter of interest not only for Anatomists but also for the Anthropologists and Forensic experts ${ }^{[1]}$.

If the sex of unknown skeleton is accessed correctly, then further investigations are likely to be more accurate and separate male and female standards may be then used for estimation of age. In addition it allows the forensic pathologists attempting to identify an individual to remove all the members of opposite sex from further consideration and the archeologists to construct a more accurate demograghic profile of the population under investigation ${ }^{[2]}$.

The nature has allowed the individual anatomical variation and departures from the set norms within each sex. In addition, these variations are affected by multiple etiological factors such as cultural, environmental and genetic elements ${ }^{[3]}$. There are various criterias for sexing of human skeletal remains:

1) Visual examination

2) Anthropometric measurements of bones

3) Anthropometric measurements with subsequent use of statistics in form of discriminate function analysis

4) X-ray examination of internal structure of section bones

5) Microscopic examination of internal structure ${ }^{[4]}$.

Hip bone is an ideal bone for sex determination because it reflects the general differences between the two sexes and also shows special adaptation of female hip bone for child bearing ${ }^{[5]}$. For sexing of human skeleton current opinion regards the hip bone as providing the highest accuracy levels ${ }^{[6]}$. Traditional non metric methods such as visual examination of bone morphology for determination of sex, depends entirely on the ability and experience of expert. It is almost impossible to assign sex with $100 \%$ certainity in all cases unless the whole skeleton is available ${ }^{[7]}$. The introduction of metric method or precise measurement method has provided the simplicity and accuracy to determine the sex of skeletal remains. Techniques which require the measurement of diameters, circumferences or cross sectional areas of tubular bones may provide the needed means for sexing fragmentary remains ${ }^{[8]}$.

\section{Corresponding Author:}

Dr. Kapil Amgain, Jawaharlal Nehru Medical College, KLE University, Belgaum

Contact Email: dr.kapilamgain@gmail.com, Contact Number: +91 9743514702 


\section{Aims And Objectives Of The Study}

To determine the sex of the hip bone using Greater Sciatic Notch by metric method in 100 dry hip bones.

\section{Materials And Methods}

One hundred specimens (dry hip bones) were collected from the skeletal collection of the Department of Anatomy, VIMS, Bellary for this prospective study. The study was conducted with the permission of ethical committee of VIMS, Bellary.

\subsection{Sampling procedure:}

The GSN of hip bone is studied by metric method and instruments such as sliding calipers, scale and protractor are used for the measurement. A total of 100 hip bones of unknown sex constituted the material for the present study. At first, the sex of the hip bones was decided on the basis certain morphological features. A sex was assigned only when there was anonymity on atleast 4 out of 5 morphological features.

The morphological features used here were:

1. Acetabular diameter

2. Obturator foramen

3. Ischiopubic ramus

4. Ischial tuberosity

5. Pre- auricular sulcus

\subsection{Inclusion criteria}

The following adult human hip bones were taken for the study which were

1. Fully ossified

2. Not broken

3. Not having any deformities with intact greater sciatic notch.

\subsection{Exclusion criteria}

The bones with the following conditions were excluded from the study

1. Deformed bones

2. Malformed bones

3. Bones with congenital anomalies.

In the present study on sex determination, in addition to its depth, width \& various indices, the total angle and posterior angles of the of the greater sciatic notch (GSN) were utilized as parameters.

The measurements were taken with the help of a sliding stainless steel calipers.

Point A - Ischial spine

Point B - Piriformis tubercle

With the help of a scale, the maximum depth (OC) is calculated between the base line (AB) and the deepest point (C) of the GSN.

1. Maximum width $(\mathrm{AB})$

2. Maximum depth ( $\mathrm{OC})$

3. Posterior segment ( OB)

4. Index $\mathrm{I}=$ Depth $\mathrm{OC} /$ width $\mathrm{AB} \times 100$

5. Index II = Posterior segment $\mathrm{OB} /$ Width $\mathrm{AB} X 100$

6. Total angle $=\lfloor\mathrm{ACB}$

7. Posterior angle $=\lfloor B C O$.

Total angle and posterior angle are measured after construction of a triangle on a paper from the above measurements in case of each bone. 


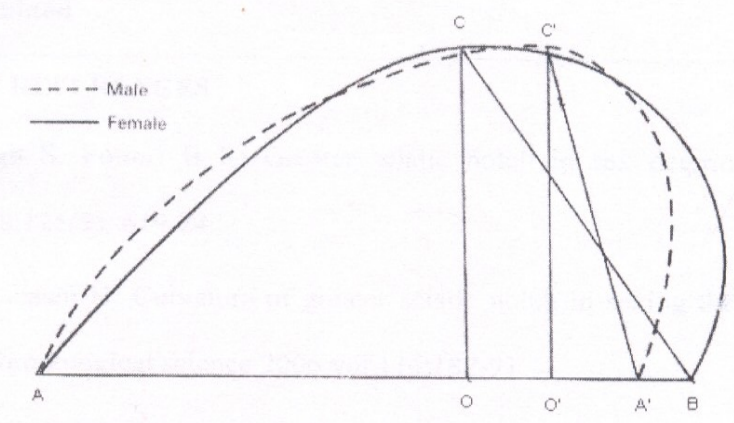

Fig1. Measurements of greater sciatic notch (continuous line for female and dotted line for male)

The angular variables of the sciatic notch were devised by triangular approximation, as illustrated in the

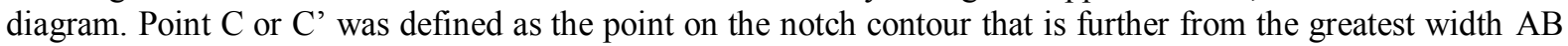
or $\mathrm{AA}^{\prime}$. The line segment $\mathrm{OC}$ or $\mathrm{OC}^{\prime}$ is the greatest depth, which intersects the width $\mathrm{AB} / \mathrm{AA}$ ' perpendicularly. Index I of the sciatic notch was defined as the depth to width ratio (OC/AB). Index II was set as the ratio of posterior segment to width $(\mathrm{OB} / \mathrm{AB})$.

Figure 2: Total nunber of hip bones

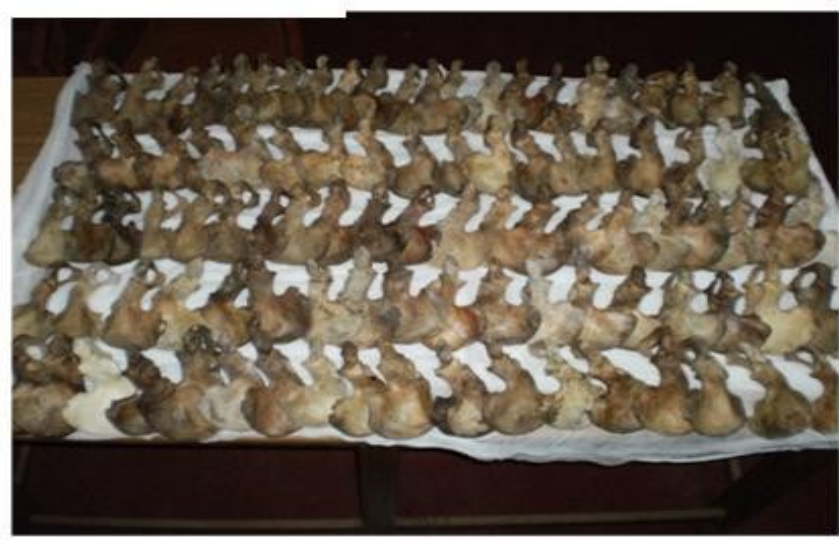

Figure 3: Showing measurement of width and death in female hip bone

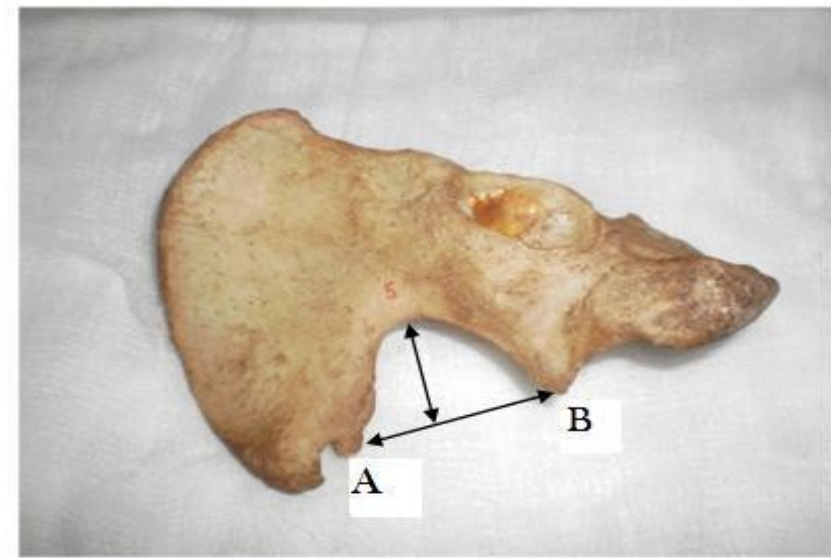

Point A - Ischial spine

Point B - Piriformis tubercle 


\section{Results}

The data obtained on different parameters were tabulated as follows [Tables 1-7]

The results for right sided male greater sciatic notch were as follows: Maximum width (AB) is $40.11 \mathrm{~mm}$ $( \pm 5.126)$, Maximum depth $(\mathrm{OC})$ is $32.34 \mathrm{~mm}( \pm 5.258)$, Width of the posterior segment $(\mathrm{OB})$ is $11.40 \pm 2.820 \mathrm{~mm}$, Total angle $60.94 \pm 6.911^{0}$, Posterior angle $19.17 \pm 4.239^{\circ}$, Index I is $80.93 \pm 67.14$ and Index II is $28.90 \pm 7.553$.

The results for right sided female greater sciatic notch were as follows: Maximum width (AB) is $47 \pm 5.148 \mathrm{~mm}$ Maximum depth $(\mathrm{OC})$ is $31.28 \pm 2.716 \mathrm{~mm}$, Width of the posterior segment $(\mathrm{OB})$ is $21.92 \pm 4.636 \mathrm{~mm}$, Total angle is $73.0 \pm-6.252$, Posterior angle is $34.32 \pm 5.047$, Index I is $67.14 \pm 6.307$ and Index II is $46.64 \pm 7.163$.

The results for left sided male greater sciatic notch were as follows: Maximum width (AB) is $39.14 \pm 2.933 \mathrm{~mm}$, Maximum depth $(\mathrm{OC})$ is $31.73 \pm 5.129 \mathrm{~mm}$, Width of the posterior segment $(\mathrm{OB})$ is $11.00 \pm 3.729 \mathrm{~mm}$, Total angle is $59.77 \pm 5.507$, Posterior angle is $19.41 \pm 6.529$, Index I is $79.45 \pm 10.01$ and Index II is $28.62 \pm 9.617$.

The results for left sided female greater sciatic notch were as follows: Maximum width (AB) is $47.33 \pm 4.472 \mathrm{~mm}$, Maximum depth (OC) is $33.61 \pm 4.002$, Width of the posterior segment(OB) is $21.67 \pm 5.122$, Total angle is $69.28 \pm 6.332$, Posterior angle is $31.89 \pm 5.312$, Index I is $71.30 \pm 8.384$ and Index II is $45.52 \pm 8.362$. These results were then compared for the sex determination. After the statistical analysis, it was found that all the parameters (especially posterior segment, total angle, posterior angle and index II) were found to be highly indicative of sex ( $>0.05)$ of unknown hip bone except depth.

Table 1: comparison of Mean Width ( $\mathrm{mm})$ of male and female hip bones of right and left side

\begin{tabular}{|l|l|l|l|l|l|l|l|}
\hline Variable & Sex & N & mean & SD & Min & Max & P value \\
\hline \multirow{2}{*}{ Width (right) } & Male & 35 & 40.11 & 5.126 & 31 & 48 & 0.000 \\
\cline { 2 - 7 } & Female & 25 & 47.00 & 5.148 & 41 & 58 & \\
\hline \multirow{2}{*}{ Width (left) } & Male & 22 & 39.14 & 2.933 & 34 & 44 & \multirow{2}{*}{$\mathrm{p}<0.05$} \\
\cline { 2 - 6 } & Female & 18 & 47.33 & 4.472 & 42 & 54 & \\
\hline
\end{tabular}

Table 2: comparison of Mean Depth ( $\mathrm{mm})$ of male and female hip bones of right and left sides

\begin{tabular}{|l|l|l|l|l|l|l|l|}
\hline Variable & Sex & n & mean & SD & Min & max & P value \\
\hline \multirow{2}{*}{ Depth (right) } & Male & 35 & 32.34 & 5.258 & 24 & 53 & $\mathrm{p}>0.05$ \\
\cline { 2 - 8 } & Female & 25 & 31.28 & 2.716 & 28 & 36 & \\
\hline \multirow{2}{*}{ Depth (left) } & Male & 22 & 31.73 & 5.129 & 23 & 39 & 0.212 \\
\cline { 2 - 7 } & Female & 18 & 33.61 & 4.002 & 29 & 40 & \\
\hline
\end{tabular}

Table 3: Comparison of Posterior segment of male and female hip bones of right and left sides

\begin{tabular}{|l|l|l|l|l|l|l|l|}
\hline Variable & Sex & n & Mean & SD & min & max & P value \\
\hline Posterior segment(right) & Male & 35 & 11.40 & 2.820 & 4 & 15 & $\mathrm{p}<0.05$ \\
\cline { 2 - 7 } & Female & 25 & 21.92 & 4.636 & 15 & 30 & \\
\hline \multirow{3}{*}{ Posterior segment(left) } & Male & 22 & 11.00 & 3.729 & 5 & 15 & \multirow{2}{*}{0.000} \\
\cline { 2 - 7 } & Female & 18 & 21.67 & 5.122 & 14 & 29 & \\
& & & & & & & \\
\hline
\end{tabular}

Table 4: comparison of Mean Total angle of male and female hip bones of right and left sides

\begin{tabular}{|l|l|l|l|l|l|l|l|}
\hline Variable & sex & n & mean & SD & Min & Max & P value \\
\hline \multirow{2}{*}{$\begin{array}{l}\text { Total } \\
\text { angle(right) }\end{array}$} & Male & 35 & 60.94 & 6.911 & 48 & 77 & \multirow{2}{*}{0.000} \\
\cline { 2 - 8 } Total angle (left) & Female & 25 & 73.00 & 6.252 & 64 & 90 & \\
\cline { 2 - 7 } & Male & 22 & 59.77 & 5.597 & 52 & 75 & 0.000 \\
\cline { 2 - 7 } & Female & 18 & 69.28 & 6.332 & 35 & 84 & \\
\hline
\end{tabular}

Table 5: Comparison of Mean Posterior angle of male and female hip bones of right and left sides

\begin{tabular}{|l|l|l|l|l|l|l|l|}
\hline Variable & Sex & n & Mean & SD & Min & max & P value \\
\hline $\begin{array}{l}\text { Posterior angle } \\
\text { (right) }\end{array}$ & Male & 35 & 19.17 & 4.239 & 6 & 25 & 0.000 \\
\cline { 1 - 7 } & Female & 25 & 34.32 & 5.047 & 24 & 44 & \\
\cline { 1 - 6 } $\begin{array}{l}\text { Posterior angle } \\
\text { (left) }\end{array}$ & Male & 22 & 19.41 & 6.529 & 10 & 27 & \multirow{2}{*}{0.000} \\
\cline { 2 - 7 } & Female & 18 & 31.89 & 5.312 & 20 & 38 & \\
\hline
\end{tabular}


Table 6: Comparison of Mean of Index I of male and female hip bones of right and left sides

\begin{tabular}{|l|l|l|l|l|l|l|l|}
\hline Variable & Sex & N & Mean & SD & min & Max & P value \\
\hline $\begin{array}{l}\text { Index } \\
\text { I(right) }\end{array}$ & Male & 35 & 80.93 & 12.57 & 59.52 & 100 & P $<0.05$ \\
\cline { 2 - 7 } & Female & 25 & 67.14 & 6.307 & 65.17 & 78.57 & \\
\cline { 1 - 1 } $\begin{array}{l}\text { Index } \\
\text { I(left) }\end{array}$ & Male & 22 & 79.15 & 10.01 & 62.5 & 100 & \multirow{2}{*}{0.012} \\
\cline { 2 - 7 } & Female & 18 & 71.30 & 8.384 & 62.5 & 79.17 & \\
\hline
\end{tabular}

Table 7: Comparison of Mean Index II of male and female hip bones of right and left sides

\begin{tabular}{|l|l|l|l|l|l|l|l|}
\hline Variable & Sex & N & mean & SD & min & Max & P value \\
\hline \multirow{2}{*}{$\begin{array}{l}\text { IndexII } \\
\text { (right) }\end{array}$} & Male & 35 & 28.90 & 7.553 & 15 & 40 & 0.000 \\
\cline { 2 - 7 } $\begin{array}{l}\text { Index II } \\
\text { (left) }\end{array}$ & Female & 25 & 46.64 & 7.163 & 34.09 & 59.09 & \\
\cline { 2 - 6 } & Female & 22 & 28.62 & 9.617 & 11.9 & 51.06 & 0.000 \\
\hline
\end{tabular}

\section{Discussion}

A study done in Turkey by Ilknur Ari, provides quantification of the features of greater sciatic notch in os coxae that should be of value in forensic and archeological analyses, especially when dealing with fragmentary bones ${ }^{[9]}$. A similar study was done in Japan by Hideo Takahashi using 164 bones (104 males and 60 females). They found that posterior angle is best discriminating variable with an accuracy of $91 \%$ and sex was determined correctly in $88 \%$ of cases ${ }^{[10]}$. In the present study also statistical difference was found to be highly significant $(\mathrm{P}>0.0001)$ between the mean values of posterior angle of greater sciatic notch of male and female hip bones for both right and left sides.

Sex determination was attempted by Rajangam et.al on 140 hip bones of unknown sex of Karnataka origin. $87.7 \%$ of hip bones could be accurately classified. The total pelvic height, sciatic notch height and the acetabular height were the most useful indicators in sexing of hip bones ${ }^{[11]}$. In the present study also statistical difference was found to be highly significant $(\mathrm{P}>0.0001)$ between the mean values of width of male and female hip bones. Jovanovic et al. reported the reliability of parameters like posterior segment, Index II, and the posterior angle as good sex discriminant factors and stressed the importance of the upper segment of the greater sciatic notch in sex determination ${ }^{[12]}$.

A Nigerian study was done by Akpan et al. using greater sciatic notch to determine the sex in 150 hip bones, the width, depth, total angle and index I were insignificant in determination of sex. Posterior angle and index II were found to be most useful in assigning sex with an accuracy of $75-90 \%{ }^{[13]}$. In the present study, it was found that all the parameters (especially posterior segment, total angle, posterior angle and index II) were found to be highly indicative of sex ( $>0.05$ ) of unknown hip bone except depth.

Patriquin et al. found the maximal width, maximal depth, and posterior segment of the greater sciatic notch to be $43.03 \mathrm{~mm}$ (in whites) and $36.96 \mathrm{~mm}$ (in blacks); $26.55 \mathrm{~mm}$ (in whites) and $22.68 \mathrm{~mm}$ (in blacks); $15.56 \mathrm{~mm}$ (in whites) and $9.31 \mathrm{~mm}$ (in blacks) for males respectively. They reported that the depth of the greater sciatic notch is more in males, but wider in females and that there is significant sex differences among both South African males and females and whites and blacks ${ }^{[14,15]}$. In the present study, the mean value of width of GSN of female right hip bone is more than the right male hip bone by $6.89 \mathrm{~mm}$. And that on the left side, female hip bone is more by $8.19 \mathrm{~mm}$ which is statistically highly significant ( $\mathrm{p}>0.0001)$. Present study shows, the mean depth of GSN of male right hip bone is more than the right female hip bone by about1 $\mathrm{cm}$ where as in left male hip bone it is less than left female hip bone by $1.88 \mathrm{~mm}$ which is statistically non-significant.

In a study of sexing of hip bones done by Singh and Potturi, the length of posterior segment of greater sciatic notch assigned sex to a higher percentage of hip bones especially female bones (95-97\%) which suggests that widening of greater sciatic notch found in females has occurred primarily in the posterior segment ${ }^{[16]}$. In the present study, the mean value of posterior segment of GSN of female right hip bone is more than the right male hip bone by $10.52 \mathrm{~mm}$ and that on the left side, female hip bone is more by $11.67 \mathrm{~mm}$ which is statistically significant $(\mathrm{p}<0.0001)$.

\section{Conclusion}

In conclusion, our results suggest that greater sciatic notch of hip bone is found to be useful in sex determination which is a critical question encountered when a bone of unknown sex is found. It was found that the mean values of width, posterior segment, posterior angle, total angle, index I and index II of males were significantly lesser than that of females both on right and left sides. Thus we would have better guidelines for archeological and forensic analyses. 


\section{References}

[1] G.I. Trancho, B. Robledo, L.I. Bueis and I.A. Sanchez, Sexual determination of femur using discriminant functions: Analysis of a Spanish population of known sex and age. J. Forensic Sci., 42(2), 1997, 181-185.

[2] J.L. Scheur and N.M. Elkington, Sex determination from metacarpals and first proximal phalanx, J Forensic Sci., 38(4), 1993, 76978.

[3] A. Leong, Sexual dimorphism of the pelvic architecture; a struggling response to destructive and parsimonious forces by natural and mate selection, McGill J Med., 9(1), 2006, 61-66.

[4] B.M. Willium, Recent developments in the identification of human skeletal material, Am J PhysAntrop.,30, $1979,459-62$.

[5] S. Shah, A. Zalawadia, S. Ruparelia, S. Patel, S.P. Rathod and S.V. Patel, Morphometric study of greater sciatic notch of dry human hip bone in Gujarat region, NJIRM, April; 2(2), 2011, 27-30.

[6] T.W. Phenice, A newly developed visual method of sexing the os pubis, Am. J. of Phys. Anthropology, 30, $297-301$.

[7] G. Singh, S. Singh and S.P. Singh, Identification of sex from tibia. J. Anat Soc India, 24, 1975, $20-24$.

[8] T.A. Black, A new method for assessing the sex of fragmentary skeletal remains: Femoral shaft circumferences. Am J Phys Anthrop.,48, 1978, 27-31.

[9] I. Ari, Morphometry of GSN on remains of male Byzantine skeletons from Nicea, Eur J Anat. 9(3), 2005, 161-5.

[10] Takahashi, Curvature of GSN in sexing of human pelvis, Anthropological science, 114(3), 2006, $187-91$.

[11] S. Rajangam, S. Janakiram and I.M. Thomas, Sexing of hip bones of Karnataka origin, J. Anat. Soc. India, 40, 1991, 105-8.

[12] S. Javanovic, S. Zivanovic and N. Lotric, The upper part of greater sciatic notch in sex determination of pathologically deformed hip bones, Acta Anat, 69, 1968, 229-38.

[13] T.B. Akpan, A.O. Igiri and S.P. Singh, Greater sciatic notch in sex differentiation in Nigerian skeletal samples, African J Med Sci, Mar- Jun; 27 (1-2), 1998, 43-6.

[14] M.L. Patriquin, S.R. Loth and M. Steyn, Metric assessment of race from the pelvis in South Africans, Forensic Sci Int, 147, 2005, 104-13.

[15] M.L. Patriquin, M. Steyn and S.R. Loth, Metric analysisof sex differences in South African black and white pelves, Forensic Sci Int, 147, 2005, 119-27.

[16] S. Singh and B.R. Potturi, Greater sciatic notch in sex determination, J. Anat, 125(30), 1978, 619-24. 